\title{
Evaluation of ground support design at Eleonore Mine via Bonded Block Modelling
}

\author{
T Garza-Cruz Itasca Consulting Group, Inc., USA \\ L Bouzeran Itasca Consulting Group, Inc., USA \\ M Pierce Pierce Engineering, USA
}

A Jalbout Newmont GoldCorp Corporation, Canada

M Ruest Newmont GoldCorp Corporation, Canada

\begin{abstract}
The ability to understand and predict the effectiveness and evolving capacity of ground support in mine accesses is paramount to the success of an operation. This paper describes the results of numerical modelling studies of ground support performance in access drifts at Eleonore Mine. These drifts are located in competent rock with undulating sub-horizontal and vertical jointing present and are subjected to mining-induced stress. The studies employ Bonded Block Models (BBM) with explicit ground support represented by the newly developed hybrid bolts in 3DEC (Itasca Consulting Group, Inc. 2016a). These models are used to back-analyse and understand past falls of ground as well as to evaluate the adequacy of the current designs to handle future conditions as mining advances. The shallow dip and undulation of the sub-horizontal joints strongly impact the back behaviour in accesses, with joints susceptible to shearing and opening under high horizontal stresses. The results of the study elucidated that the falls of ground experienced at the mine are due to the bolts in the back (\#6 rebar) being heavily strained locally through sub-horizontal joint shearing as nearby stoping took place, causing them to rupture. As foreseen by the mine in 2016, the model results confirm the need for bolts with higher shearing capacity to support the on-ore drifts. Both D-bolts and \#7 rebar were analysed as alternatives with the model and shown to provide superior deformation compatibility, which agrees with experience on the mine. D-bolts offer a less stiff response (which increases survivability under highly localised deformations), while \#7 rebar offers a higher yield strength. This paper describes how numerical models that allow for realistic fracturing and bulking of the rock mass along with explicit representation of pre-existing discontinuities can be used to more realistically model ground support performance in competent rock.
\end{abstract}

Keywords: ground support, Bonded Block Model, BBM, stoping

\section{Introduction}

Eleonore Mine, located in the James Bay area of Northern Quebec, started commercial production in 2015 and soon experienced ground instabilities despite the shallow depth of operation (200 to $600 \mathrm{~m})$ and good rock mass quality (intact uniaxial compressive strength (UCS) $\sim 160 \mathrm{MPa}$ ). Support design changes implemented in 2016 successfully reduced instabilities, but the mechanisms behind the improved performance were not fully understood. For this reason, in 2018 , the mine decided to conduct drift-scale geomechanical numerical analyses to better understand the mechanisms and interactions between the rock and ground support leading to the performance of the initial and revised support designs, which would also elucidate the new design applicability as mining progresses to deeper horizons. 


\section{Background}

The orebody at Eleonore is comprised of multiple steeply dipping lenses of narrow thickness and variable grade. Access to the mine is through the hanging wall due to the presence of water above the footwall, and mining fronts often converge toward large intersections. The dominant Greywacke unit is strong and brittle with a UCS of approximately $160 \mathrm{MPa}$. Persistent sub-horizontal joints at close spacing (30 to $50 \mathrm{~cm}$ ) dominate in horizons 1 to 4 (down to $800 \mathrm{~m}$ deep), with some other crossing vertical joints present, leading to a GSI in the range of $60-65$.

\section{$2.1 \quad$ In situ stress}

Stress measurements at two elevations are available at Eleonore Mine, which indicate that the major principal stress is horizontal and trending at 064 degrees, and that the other two principal stresses are vertical and horizontal as shown in Table 1. The stress measurements suggest that the minor horizontal stress and the vertical stress are very similar in magnitude (consistent with the overburden weight); therefore, they have been assumed to be the same for the modelling exercise $\left(\sigma_{2}=\sigma_{3}\right)$. Based on the observations and backanalyses of significant seismicity and instabilities in horizons 1 and 2 (Bouzeran et al., 2019), along with the stress measurements at depth, it was concluded that the horizontal stress is non-zero at the ground surface, which is typical of regions that have experienced post-glacial rebound such as the northern part of Canada. The same uniform gradient is assumed for all the stress components. This corresponds to a $\mathrm{K}$ ratio $\left(\sigma_{\mathrm{H}} / \sigma_{\mathrm{V}}\right)$ of about 5 at $200 \mathrm{~m}$ depth and about 3 at $400 \mathrm{~m}$ depth, which is realistic when compared to stress ratio trends from other sites (Hoek \& Brown 1980). The in situ stress magnitudes and orientations used in the numerical models are summarised in Table 1.

Table 1 In situ stress regime assumed in all numerical models

\begin{tabular}{cccc}
\hline Stress $(\mathrm{MPa})$ & Magnitude & Trend & Plunge \\
\hline$\sigma_{1}$ & $19+27.5 \times$ depth $(\mathrm{km})$ & 64 & 0 \\
$\sigma_{2}$ & $27.5 \times$ depth $(\mathrm{km})$ & 153 & 0 \\
$\sigma_{3}$ & $27.5 \times$ depth $(\mathrm{km})$ & 0 & 90 \\
\hline
\end{tabular}

\section{$3 \quad$ Modelling the excavation using Bonded Block Modelling}

The Bonded Block Model (BBM) in 3DEC (Itasca Consulting Group, Inc. 2016a) was used to simulate the response an excavation (on-ore drift or intersection) would have to the advancement of the excavation face as it is being mined as well as additional induced stresses as a result of nearby mining of stopes. 3DEC was selected as it can be used to simulate a massive rock mass as bonded polyhedral elements (tetrahedral in this case) that can break at their subcontacts as a result of stress concentrations, mimicking the initiation of cracks that can coalesce and/or propagate to fracture the rock mass. This results in an emergent damage pattern with associated bulking. The 3DEC approach differs from particle-based methods such as PFC3D (Itasca Consulting Group, Inc. 2014) in its inherent ability to represent a zero initial porosity condition, as well as interlocked irregular block-shapes, that provides resistance to block rotation (moments) after contact breakage. This allows one to mimic the high UCS to tensile strength ratios and friction angles typically exhibited by hard rock. These processes tend to dominate the rock mass behaviour in low confinement zones near excavations. Additionally, 3DEC allows for joints to be explicitly represented by overprinting them as cuts on the intersecting blocks.

\subsection{Bonded Block Model drift-scale model}

A rock mass sample was constructed by assembling a collection of interlocked tetrahedral blocks with an approximate edge length of 4-6 cm using Griddle ${ }^{T M}$ (Itasca Consulting Group, Inc. 2016b) and importing them into 3DEC. The block contacts are populated with pertinent material properties following the methodology 
described by Garza-Cruz \& Pierce (2014). The results from a point load test campaign performed at Eleonore that targeted both axial and diametral samples (suggesting homogenous rock strength) were assembled into a cumulative tensile strength distribution (Figure 1), which was directly used as input to populate the BBM model. The strength of the contacts between the tetrahedral blocks forming the BBM sample are directly informed by randomly sampling the cumulative tensile strength distribution derived from the point load test campaign. The cumulative strength distribution is used to account for strength heterogeneity. The cohesion of the contacts was set to be 2.5 times the assigned tensile strength. This cohesion to tensile strength ratio was based on a sensitivity study in which such ratios produced a macro UCS to tensile strength ratio of the order of 10-20. In all models, the blocks were defined as elastic. The Young's modulus of the blocks was assumed to be that of the intact Greywacke ( $39 \mathrm{GPa}$ ). Upon breakage of the contacts, all tensile and cohesive strength is assumed to be lost; therefore, the residual tensile and cohesion properties are set to zero. The block and block-contact micro-mechanical properties of the Greywacke BBM are summarised in Table 2.
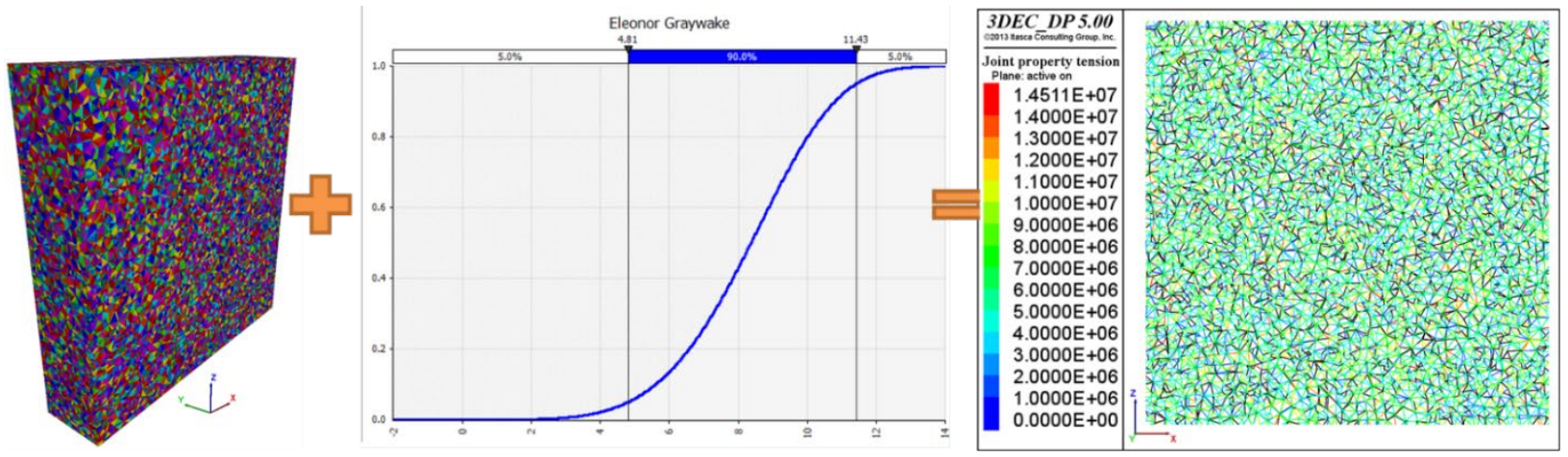

Figure 1 Bonded Block Model sample generation procedure. The contacts between a 3DEC collection of tetrahedral blocks (left) are populated by randomly selecting a value from the Eleonore Greywacke cumulative distribution of tensile strength (centre) derived from a systematic point load test campaign. The picture on the right shows a colour contour of the magnitude of the tensile strength at each block contact on a vertical cross-section through the sample

Table 2 Block and contact micro-mechanical properties used in the Bonded Block Model

\begin{tabular}{ll}
\hline Block properties & \\
\hline Young's modulus & $39 \mathrm{GPa}$ \\
Poisson's ratio & 0.25 \\
Density & $2,750 \mathrm{~kg} / \mathrm{m}^{3}$ \\
\hline Contact properties & \\
\hline Normal stiffness & $920 \mathrm{GPa} / \mathrm{m}$ \\
Shear stiffness & $460 \mathrm{GPa} / \mathrm{m}$ \\
Peak friction angle & $35^{\circ}$ \\
Residual friction angle & $35^{\circ}$ \\
Dilation angle & $10^{\circ}$ \\
Peak tensile strength & Randomly sampled from \\
& distribution in Figure 1 \\
Residual tensile strength & 0 \\
Peak cohesive strength & $2.5 \times$ tensile strength \\
Residual cohesive strength & 0 \\
\hline
\end{tabular}


A $36 \mathrm{~m}$ high, $18 \mathrm{~m}$ diameter BBM sample was numerically tested under uniaxial and triaxial conditions to obtain the emergent large-scale rock block strength, elastic modulus and friction angle of the constructed synthetic rock (before the joints were imprinted on the sample). This resulted in an emergent rock block strength of $40 \mathrm{MPa}$ with an emergent rock block Young's modulus of $32 \mathrm{GPa}$ and friction angle of $40^{\circ}$. This strength would correspond to the tangential stress limit at an excavation boundary when failure/spalling would be predicted to initiate. Figure 2 shows the emergent axial stress versus axial strain curves of tested BBM samples at different confinement levels. It is interesting to note that the BBM samples show that with increasing confining pressure:

- The peak strength increases.

- There is a transition from brittle to more ductile behaviour.

- The region encompassing the peak of the curve flattens and widens.

- The post-peak residual strength increases.

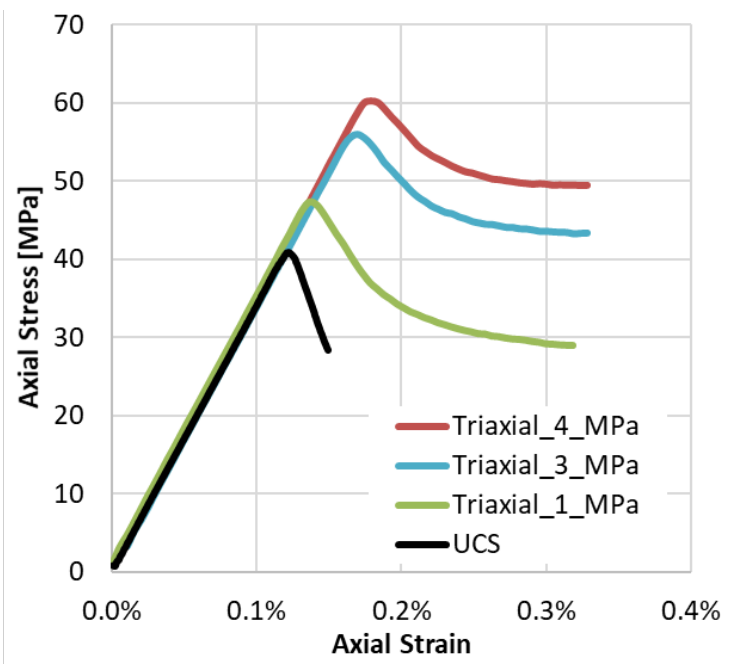

Figure 2 Emergent stress versus strain response of modelled Graywacke using Bonded Block Model tested at different confinement levels

Additionally, the emergent dilation angle as a function of confinement was also obtained, as this has a direct impact on the bulking behaviour of the rock exercising the ground support. Figure 3 shows two things: the volumetric strain versus axial strain behaviour of a BBM sample of Graywacke tested under triaxial conditions at $1 \mathrm{MPa}$ confinement; and a summary of the dilation angle sensitivity to different confinement levels showing an emergent dilation angle of $\sim 28^{\circ}$ at $4 \mathrm{MPa}$ of confinement and $\sim 48^{\circ}$ at $0.5 \mathrm{MPa}$ of confinement.

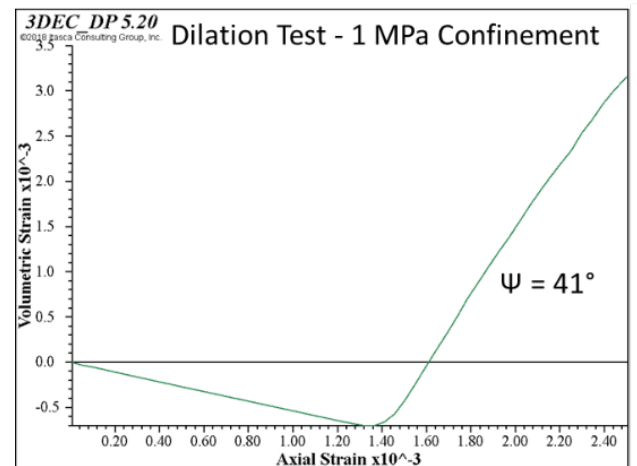

(a)

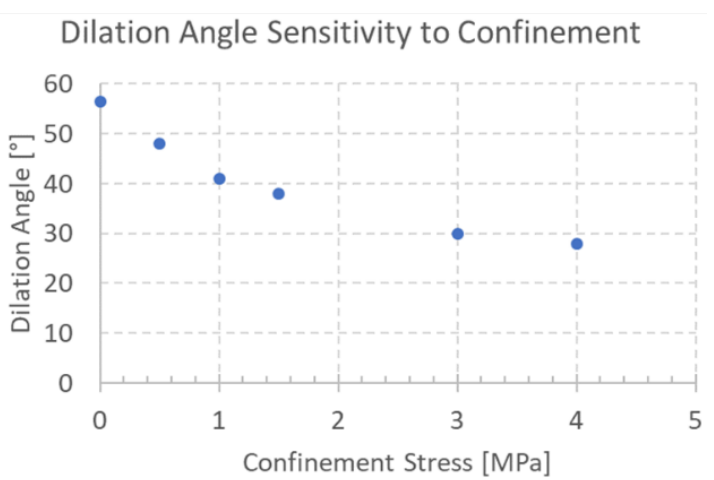

(b)

Figure 3 (a) Volumetric strain versus axial strain behaviour of a Graywacke BBM sample tested triaxially under $1 \mathrm{MPa}$ confinement to obtain emergent dilation angle $\left(41^{\circ}\right)$; (b) Emergent dilation angle sensitivity to confinement of the numerically simulated Graywacke 
Joint sets were subsequently explicitly overprinted using the block cutting capabilities in 3DEC. Persistent sub-horizontal undulating joints present in the Greywacke in the horizons modelled were explicitly represented with an average global dip of $5^{\circ}$ (based on a joint mapping campaign conducted by MDEng (Oke \& Kalenchuk 2017)). These sub-horizontal joints form beds with randomly variable thickness between 0.3-0.5 m. Additionally, the bed undulation is randomly phased to avoid uniform/parallel beds (local bed dip varies from $-10^{\circ}$ to $10^{\circ}$ with a $4 \mathrm{~m}$ undulation cycle).

Vertical joints are also present but are far less persistent than the horizontal joints. Thus, the vertical joints are explicitly represented with a persistence of $2 \mathrm{~m}$ and a spacing of $1.5 \mathrm{~m}$.

Figure 4 shows the geometry of the BBM model to evaluate ground support performance in a $5 \times 5 \mathrm{~m}$ drift. Each coloured layer in the roof is defined by the persistent sub-horizontal joint set, and vertical joints are shown in black. It is important to note that the beds are formed by bonded blocks (approximate edge length of 4-6 cm) to allow for intra-bed fracturing as a response to induced stresses.

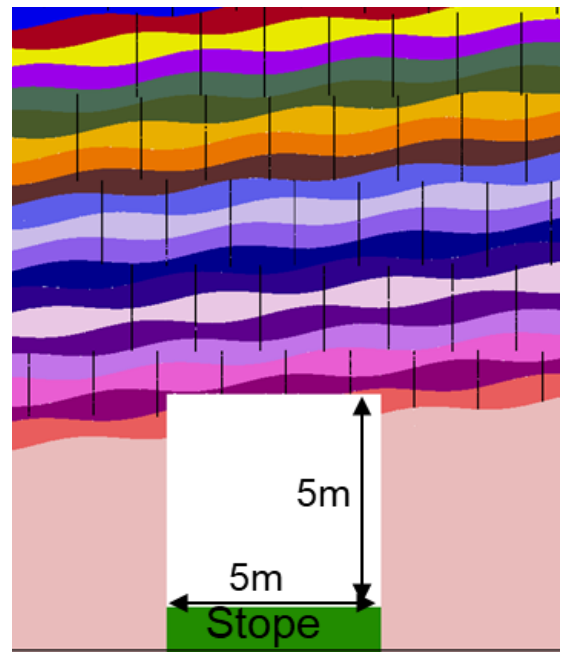

Figure 4 Geometry of Bonded Block Model built in 3DEC to evaluate ground support performance in a $5 \times 5 \mathrm{~m}$ drift. Each coloured layer in the roof is defined by a persistent sub-horizontal joint set, and vertical joint intersections are shown in black

\subsection{Geometry and sequence}

Two types of excavation geometries were studied: single drifts that are typically $5 \mathrm{~m} \times 5 \mathrm{~m}$; and large intersections, with spans that usually vary between 10 and $14 \mathrm{~m}$ in three dimensions.

Although the BBM models are geometrically three-dimensional, the out-of-plane thickness used is $1.2 \mathrm{~m}$ (to account for the ground support pattern spacing and allow for an extra degree of freedom in fracture propagation) with plane-strain conditions assumed in the out-of-plane direction, effectively representing an infinitely long drift.

In order to represent the span of an intersection using the described geometry, the radius factor of the equivalent 2D, plain-strain excavation is set equal to the radius factor of the $3 D$ intersection, which corresponds to a span of $10 \mathrm{~m}$ for the modelled intersection. The Radius Factor (RF) is an approach developed by Milne et al. (1996) to study the stability of irregular geometries, like the intersections at Eleonore.

The drift-scale modelling exercise focuses on the behaviour of the roof of the excavations. The back is indeed the most vulnerable part of the openings at Eleonore because of the high horizontal stress and the presence of sub-horizontal joints. Therefore, to optimise the computational time, representation of the walls and floor of the access is simplified and modelled elastically without any support. Additionally, the back has been assumed to be flat for simplicity (the drift backs at the mine range from flat to arched). It is important to note that an arched back would improve the stability of the drift back as it would make it kinematically more stable, so the drifts simulated here would be inherently less stable. 
The excavation sequence at Eleonore is modelled as follows:

1. Simulate advance of the drift excavation face by incrementally relaxing the perimeter of the excavation to a level consistent with a face distance of $30 \mathrm{~cm}$ ( $30 \%$ of tunnel maximum closure and $\sim 80 \%$ of tunnel deconfinement).

2. The primary support is installed.

3. The drift is fully relaxed, representing final excavation of the drift (which loads the support).

4. The secondary support is installed (if applicable).

5. The stope below the drift is mined. This induces high stresses on the back of the excavation, which could also occur due to mining of adjacent stopes.

The major in situ stress direction is perpendicular to the modelled drift and so is representative of an on-ore drift (parallel to average orebody strike). The excavation sequence and associated induced stresses are depicted in Figure 5.

\section{Drift excavation induces elevated stresses on the drift back}
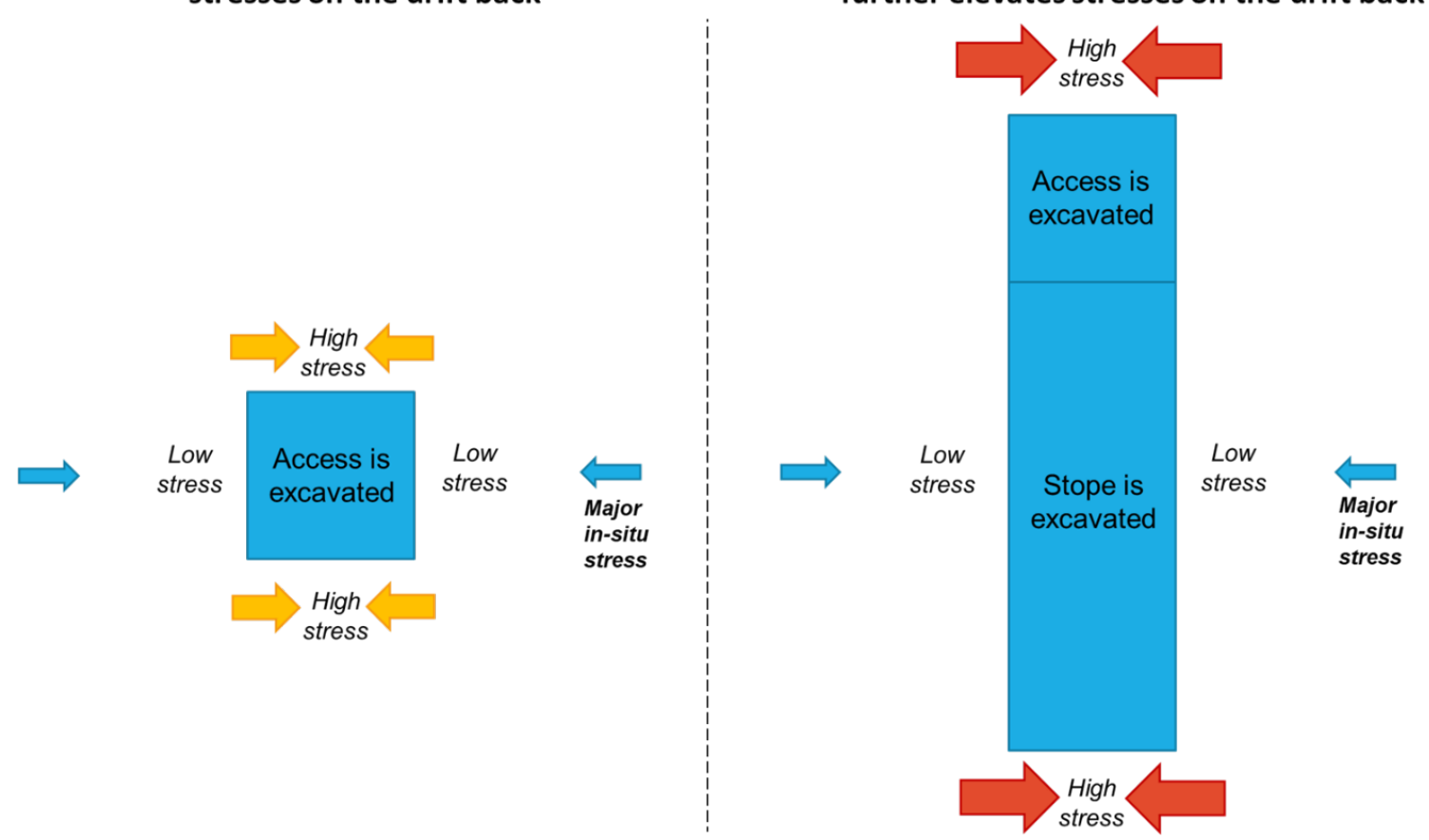

Figure 5 Excavation sequence and associated induced stresses on the back of the access. Initial induced stresses result from the excavation of the access, while additional induced stresses result from the excavation of the stope below

It is important to note that the additional stress concentration on the drift back as a result of the excavation of the stope below could also be induced by other local factors that increase stress and could occur in accesses of the orebody. In other words, modelling stoping below a drift is a way to simulate further stressing of the back, but similar back conditions could be encountered in different situations, such as a haulage drift located in a stress corridor or an intersection located in the centre of a highly stressed secondary stope.

\subsection{Modelling ground support}

For each support design evaluated, bolts are modelled explicitly using the newly developed hybrid bolts in $3 D E C$, and their properties are calibrated to reproduce the specified capacity and behaviour observed experimentally in pull-out and shear tests (Bouzeran et al. 2016). The properties of the different ground support elements evaluated are summarised in Table 3. 
Table 3 Ground support input properties used in the numerical models

\begin{tabular}{lcccccc}
\hline & Rebar \#6 & $\begin{array}{c}\text { Super } \\
\text { Swellex }\end{array}$ & Split Set 35 & Cables & $\begin{array}{c}\text { D-bolt (free } \\
\text { section) }\end{array}$ & $\begin{array}{c}\text { D-bolt } \\
\text { (anchors) }\end{array}$ \\
\hline Area $\left(\mathrm{m}^{2}\right.$ ) & $2.84 \mathrm{e}-4$ & $3.11 \mathrm{e}-4$ & $2 \mathrm{e}-4$ & $1.99 \mathrm{e}-4$ & $3.14 \mathrm{e}-4$ & $3.14 \mathrm{e}-4$ \\
Young's modulus (Pa) & $2 \mathrm{e} 11$ & $2 \mathrm{e} 11$ & $2 \mathrm{e} 11$ & $2 \mathrm{e} 11$ & $2 \mathrm{e} 11$ & $2 \mathrm{e} 11$ \\
Bond stiffness (N/m/m) & $3 \mathrm{e} 8$ & $5 \mathrm{e} 7$ & $8 \mathrm{e} 7$ & $1.5 \mathrm{e} 8$ & $2 \mathrm{e} 8$ & $2 \mathrm{e} 8$ \\
Bond strength (N/m) & $4 \mathrm{e} 5$ & $2.4 \mathrm{e} 5$ & $3.3 \mathrm{e} 4$ & $2.1 \mathrm{e} 5$ & 0 & $8 \mathrm{e} 5$ \\
Dowel stiffness (N/m) & $2 \mathrm{e} 7$ & $2.6 \mathrm{e} 7$ & $1.8 \mathrm{e} 7$ & $9 \mathrm{e} 6$ & $2 \mathrm{e} 7$ & $2 \mathrm{e} 7$ \\
Axial strain limit (m/m) & 0.2 & 0.025 & 0.2 & 0.2 & 0.2 & 0.2 \\
Dowel strength (N) & $7.28 \mathrm{e} 4$ & $5 \mathrm{e} 4$ & $3.3 \mathrm{e} 4$ & $5 \mathrm{e} 4$ & $7.28 \mathrm{e} 4$ & $7.28 \mathrm{e} 4$ \\
Axial strength (N) & $1.5 \mathrm{e} 5$ & $2.4 \mathrm{e} 5$ & $8 \mathrm{e} 4$ & $2 \mathrm{e} 5$ & $1.6 \mathrm{e} 5$ & $1.6 \mathrm{e} 5$ \\
Dowel strain limit $(\mathrm{m} / \mathrm{m})$ & 0.31 & 0.49 & 0.5 & 0.31 & 0.31 & 0.31 \\
Dowel length $(\mathrm{m})$ & 0.1 & 0.1 & 0.1 & 0.1 & 0.1 & 0.1 \\
Segment length $(\mathrm{m})$ & 0.1 & 0.1 & 0.1 & 0.1 & 0.1 & 0.1 \\
\hline
\end{tabular}

The hybrid bolt is a one-dimensional reinforcement element that features a more realistic resistance to fracture shear displacement designed to simulate a rockbolt in a jointed rock mass. The hybrid bolt consists of two components: a 'cable' with a specified tensile strength and stiffness that resists shear along its length (i.e. pull-out), and a 'dowel' segment that resists lateral shear where the bolt crosses a rock joint. The dowel really represents a set of complex mechanical effects, including bending of the steel bolt, crushing of the grout, crushing of the host rock etc. In 3DEC, this is simply represented by a spring resisting shear on the joint, but by careful calibration of stiffness and strength parameters, the three stages of load response (elastic, yield and plastic stages) typically observed in laboratory tests can be obtained.

\subsection{Key assumptions and limitations of the model}

In all simulations presented here, the ground support is assumed to be encapsulated within high quality grout along the full length of each bolt. Additionally, the plates have been modelled as elastic elements, so they cannot fail. In reality, installation factors such as grout quality, true grouted length and poor plate installation could have a negative effect on ground support performance. These can be analysed with the model but have been excluded from this specific study. Additional adverse conditions such as corrosion or dynamic loading are also not taken into account here.

For simplicity, the back of the excavations in the modelling work presented here has been assumed as flat. In reality, the backs range from flat to arched, with arched backs resulting in an inherently more stable condition.

While discontinuum approaches such as the Discrete Element Method (DEM) have been shown to realistically simulate the initiation, propagation and coalescence of cracks leading to face-parallel fracturing (spalling), as well as the rock mass strength dependency on confinement (Damjanac et al. 2007; Lan et al. 2010; Garza-Cruz et al. 2014), these DEM models are still computationally expensive. It is important to mention that the BBM is intended to provide enough pathways in 3D to allow the synthetic rock to develop fractures that would be representative of the fracturing that would occur in a typical excavation through the rock mass of interest. It is not meant to represent the fracturing occurring at the grain level. In a BBM, the fracturing would follow the minimum energy requirement path, with a more 'jagged' response with larger block size, while smaller block sizes would develop a somewhat 'smoother' oscillation around the same mean path. For practical applications, a balance between run time (directly impacted by the block size modelled) and realistic 
behaviour need to be struck, knowing that the minimum emergent fragment size is constrained by the block size selected.

Additionally, in cases where the bending of beds needs to be captured, the authors recommend having a minimum of 5-8 blocks across the thickness of the bed to be able to capture the bending behaviour.

\section{$4 \quad$ Ground support design evaluation}

Instabilities and falls of ground have been experienced at Eleonore Mine as a result of overstressing of the back of drifts and intersections due to nearby mining. As a result, the mine changed the ground support design to mitigate this, successfully reducing instabilities. However, the mechanism behind the poor performance of the original design along with the improved performance of the revised designs were not fully understood. In turn, the effectiveness and adequacy of the revised designs in evolving conditions or deeper horizons was also not fully understood. This is important, as the ability to quantify how much of the ground support capacity has been consumed, and consequently, how much remaining capacity exists, is central to the adequate selection of supplemental support.

The original design (Design 1 in Table 4) at Eleonore consisted of $2.4 \mathrm{~m}$ long \#6 rebar (on a $1.2 \times 1.2 \mathrm{~m}$ spacing) with $1.5 \mathrm{~m}$ long Split Set 35 (on a $1.2 \times 1.2 \mathrm{~m}$ spacing) with no secondary support.

Table 4 Support design evaluated (Designs 1-3 were done for level $440 \mathrm{~m}$ and Design 4 for level $200 \mathrm{~m}$ )

\begin{tabular}{|c|c|c|c|c|}
\hline & Design 1 & Design 2 & Design 3 & Design 4 \\
\hline \multirow[t]{2}{*}{ Primary } & $\begin{array}{l}2.4 \mathrm{~m} \text { long \#6 rebars, } \\
1.2 \mathrm{~m} \text { spacing }\end{array}$ & $\begin{array}{l}2.4 \mathrm{~m} \text { long } D \text {-bolts, } \\
1.2 \mathrm{~m} \text { spacing }\end{array}$ & $\begin{array}{l}2.4 \mathrm{~m} \text { long \#7 rebars, } \\
1.2 \mathrm{~m} \text { spacing }\end{array}$ & $\begin{array}{l}2.4 \mathrm{~m} \text { long \#6 rebars, } \\
1.2 \mathrm{~m} \text { spacing }\end{array}$ \\
\hline & $\begin{array}{l}1.5 \text { m long Split set } 35, \\
1.2 \mathrm{~m} \text { spacing }\end{array}$ & $\begin{array}{l}1.7 \mathrm{~m} \text { long } D \text {-bolts, } \\
1.2 \mathrm{~m} \text { spacing }\end{array}$ & $\begin{array}{l}1.8 \mathrm{~m} \text { long \#7 rebars, } \\
1.2 \mathrm{~m} \text { spacing }\end{array}$ & \\
\hline \multirow[t]{2}{*}{ Secondary } & None & None & None & $\begin{array}{l}4.5 \mathrm{~m} \text { long Super } \\
\text { Swellex, } 1.8 \mathrm{~m} \text { spacing }\end{array}$ \\
\hline & & & & $\begin{array}{l}10 \mathrm{~m} \text { long unplated } \\
\text { single strand cables, } \\
1.8 \mathrm{~m} \text { spacing }\end{array}$ \\
\hline
\end{tabular}

The performance of the ground support was evaluated at a depth of $440 \mathrm{~m}$. Following the sequence described in Section 3.2, the support was installed $30 \mathrm{~cm}$ from the face of the excavation, followed by full drift advancement (full relaxation). The top portion of Figure 6 shows the drift condition after full excavation of the drift but before excavation of the stope below. At this point, rebars are being loaded (up to their capacity of $150 \mathrm{kN}$ ) mostly in the central part of the back where the highest vertical displacement is taking place; meanwhile, the split sets are not taking much load. At this point, although some of the support has yielded, it is behaving adequately relative to current demand and the drift is stable.

When stoping below the drift takes place (bottom of Figure 6), the sub-horizontal joints experience shearing and opening under the high induced horizontal stresses ( $90 \mathrm{MPa}$ ) while intra-bed fracturing of the rock and bulking is also taking place, further exercising the ground support. As a consequence, the rebars get locally sheared and axially loaded where they intersect the sub-horizontal joints, to the point of rupture. After the rebars have ruptured, the wedge-shaped volume of rock in the central part of the back is free to fall down; the split sets cannot prevent such movement and are being pulled out, offering limited contribution to the support system. At this point, a fall of ground is predicted, which is inline with mine experience.

An alternative ground support design is evaluated (Design 2 in Table 4), which consists of $2.4 \mathrm{~m}$ long D-bolts (on a $1.2 \times 1.2 \mathrm{~m}$ spacing) with $1.7 \mathrm{~m}$ long D-bolts (on a $1.2 \times 1.2 \mathrm{~m}$ spacing) with no secondary support. D-bolts are a smooth steel bar with a number of deformed sections that act as anchor points along its length. 

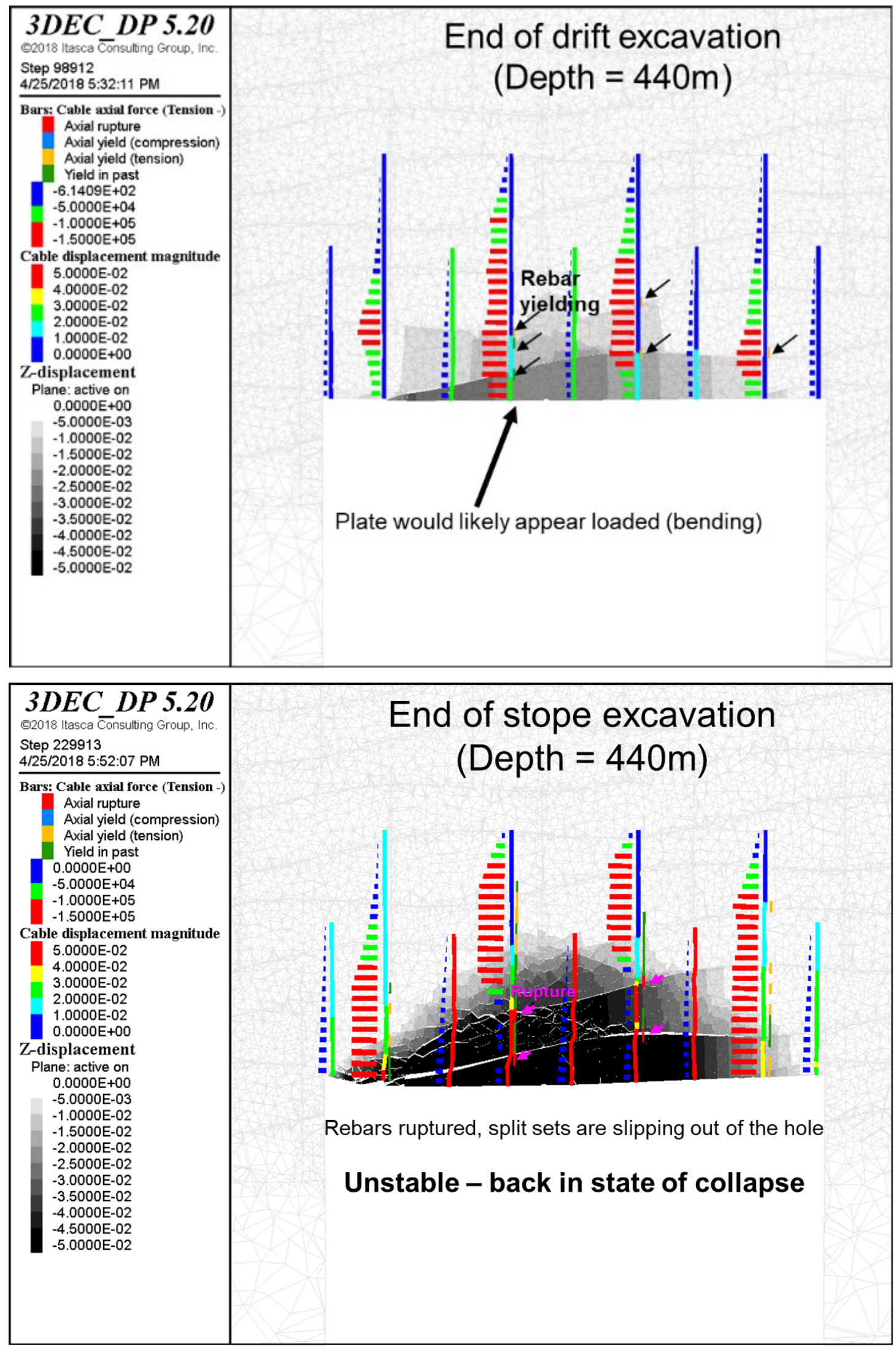

Figure 6 On-ore drift at $440 \mathrm{~m}$ depth with Design 1. Rock vertical displacement (greyscale), bolt's axial force (bar graph on bolt's left side), and cable displacement (contoured on bolt itself) - State after full drift excavation (top). State after stope under the drift has been excavated inducing high stresses on the back (bottom) 
As before, the performance of the ground support design was evaluated at a $440 \mathrm{~m}$ depth drift with support installed $30 \mathrm{~cm}$ from the face of the excavation. The top portion of Figure 7 shows the drift condition after full excavation of the drift but before excavation of the stope below. At this point, D-bolts in the central part of the back are being loaded (up to their capacity $\sim 160 \mathrm{kN}$ ) where the highest vertical displacement of the ground is taking place. As D-bolts are exercised, the strain is distributed over the long, smooth sections between anchor points, spreading the localisation of shearing and stretching. Some D-bolts get loaded at the collar, which indicates the possibility of some plates appearing loaded or bent. At this point, the support is behaving adequately, and the drift is stable.

As stoping below the drift takes place (bottom of Figure 7) and the sub-horizontal joints experience shearing and opening due to the high induced stresses, the D-bolts get further loaded. Several sections reach their load capacity, but only $50 \%$ of the maximum shear strain capacity is consumed in sections subjected to shearing. The reason for this is that $\mathrm{D}$-bolts have a more compliant response than grouted rebar because the stretch is distributed over the smooth sections between the anchor points of the D-bolts, which results in a lower strain. This is in contrast to the stiffer response of fully grouted rebars, which tend to localise the deformation over a short length where they intersect the shearing sub-horizontal joints. Drifts supported with Design 2 are predicted to be stable even when the induced stresses on the back reach $90 \mathrm{MPa}$, with about $50 \%$ shear strain capacity left.

A third design, using fully grouted and plated \#7 rebar, is evaluated under the same conditions (Design 3 in Table 4). The top portion of Figure 8 shows the drift condition after full excavation of the drift but before excavation of the stope below. At this point, rebars are being loaded (up to their capacity $175 \mathrm{kN}$ ) mostly in the central part of the back where they intersect the sub-horizontal joints and most of the relaxation is taking place, utilising their load capacity; however, the support is behaving adequately and the drift is stable.

As stoping below the drift takes place (bottom of Figure 8) and the sub-horizontal joints experience intense shearing and opening due to the high induced stresses, the rebars get locally sheared and axially loaded where they intersect the sub-horizontal joints. Although most rebars have yielded in multiple locations, they are still being exercised within capacity. One of the rebars (third from the left) has reached $90 \%$ of its capacity at an intersection with the sub-horizontal joint; however, the rest of the rebars have consumed up to $70 \%$ of their capacity. This ground support design is predicted to be sufficient to hold the ground together under the modelled conditions (induced back stresses of $\sim 90 \mathrm{MPa}$ ), which matches field observations. However, secondary support may be needed if this support design is to be implemented under higher induced stress conditions.

In general, the modelling results suggest that the \#6 rebars (Design 1 ) are heavily loaded at the end of the excavation before the stope is even mined (little load capacity left). The \#6 rebars are susceptible to rupture when the back is further loaded as they are stiff and subjected to intense shearing and opening local to the sub-horizontal joints, while the split-sets carry much lower loads. This indicates, as observed by the mine, that under the evaluated conditions, Design 1 is not adequate and falls of ground are predicted.

When supported with D-bolts, the support is loaded and several sections reach their maximum load capacity (16 t) but only $50 \%$ of the maximum shear strain capacity is reached, as the D-bolts are able to spread local shear and axial solicitation along the smooth sections (i.e. between anchors), offering a less stiff response (which increases survivability under highly localised deformations); hence, keeping the back in place. Both shorter and longer D-bolts bring significant contribution to the support system.

When supported by Design 3 (\#7 rebar), the support is loaded to capacity (yielding sections of some of the bolts) but the system is still able to survive the additional demand imposed by the high induced-stresses on the back. This is because although stiff, \#7 rebar offer a higher yield strength capacity than their \#6 rebar counterparts. It is interesting to compare the results from Design 1 (long \#6 rebars with short split sets) with the results of Design 3, since the length of the bolts and bolting pattern are similar. While in Design 1 the short split-sets were not contributing much to the system stability and the longer \#6 rebars exceeded their strain capacity, with Design 3, both shorter and longer \#7 rebar provide significant contribution to the support system, which allows the back to remain stable. 


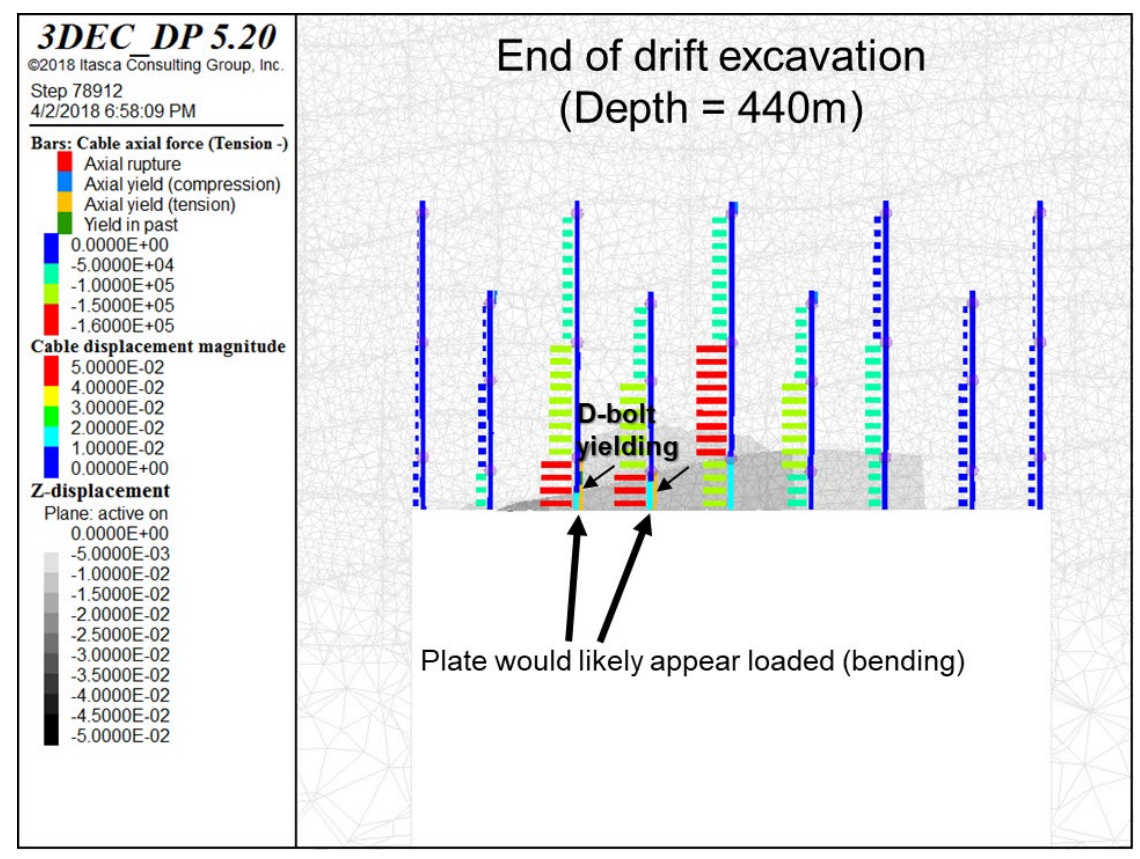

(a)

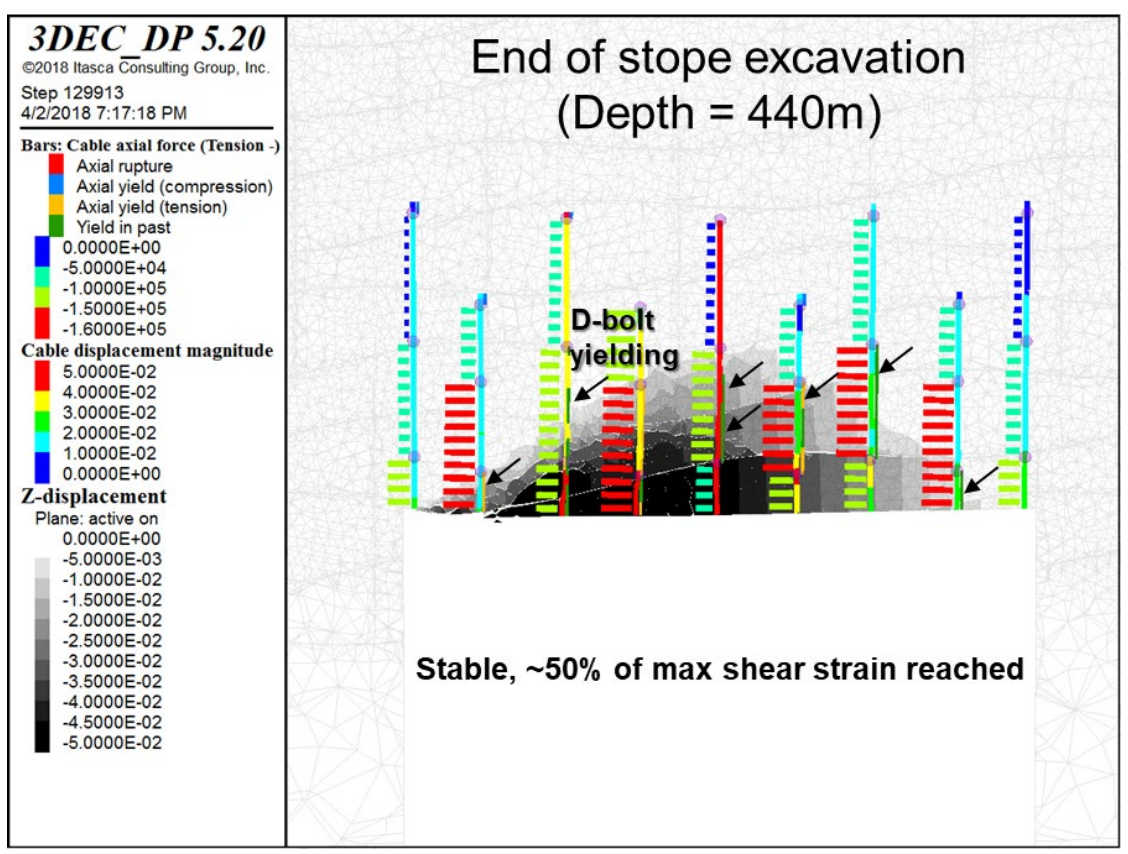

(b)

Figure 7 On-ore drift at $\mathbf{4 4 0} \mathrm{m}$ depth with Design 2. Rock vertical displacement (greyscale), bolt's axial force (bar graph on bolt's left side), and cable displacement (contoured on bolt itself), spheres on the bolts represent D-bolt anchor points - State after full drift excavation (a). State after stope below the drift has been excavated inducing high stresses on the back (b) 


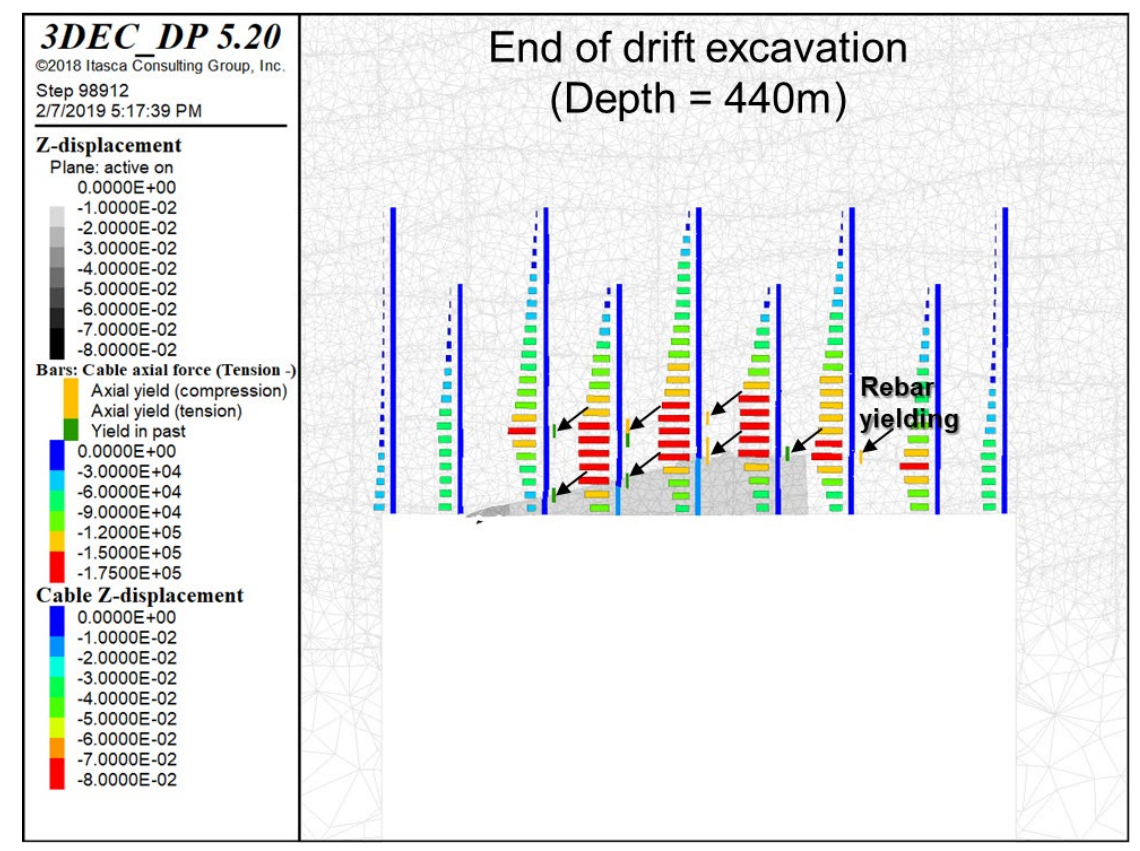

(a)

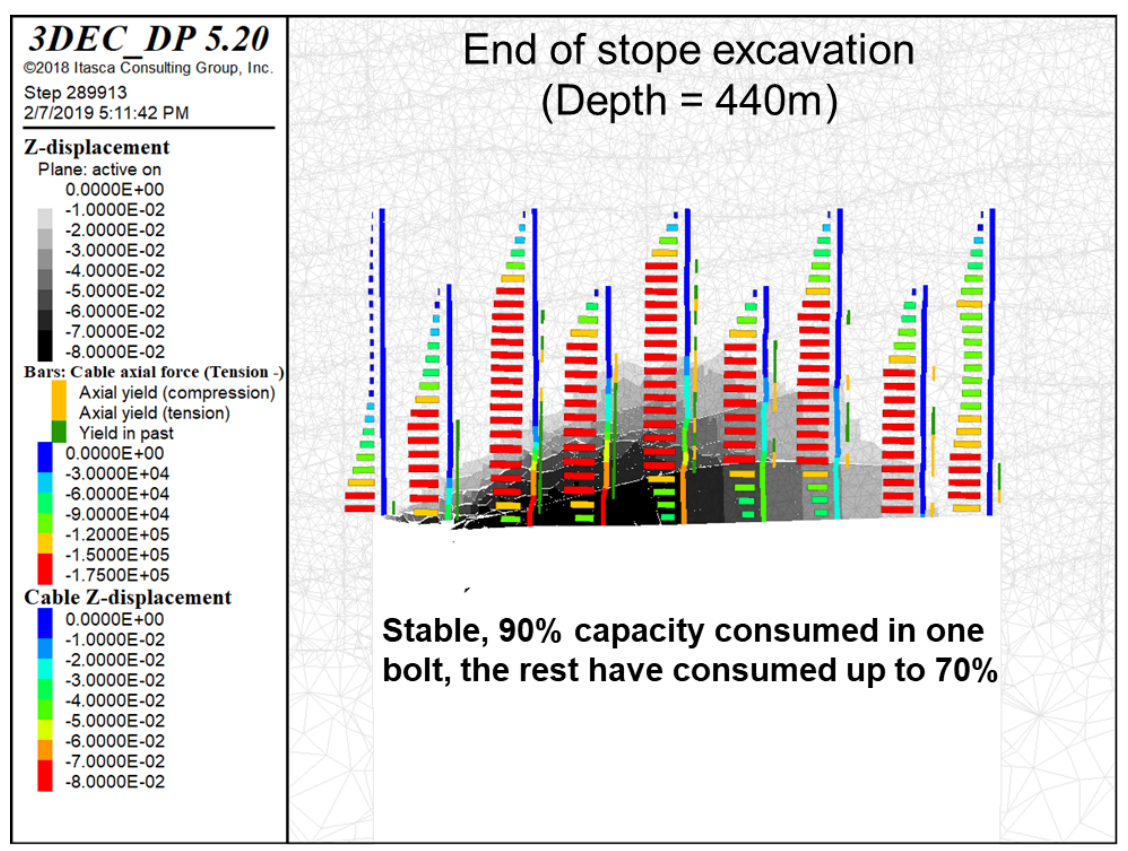

(b)

Figure 8 On-ore drift at $440 \mathrm{~m}$ depth with Design 3. Rock vertical displacement (greyscale), bolt's axial force (bar graph on bolt's left side), and cable displacement (contoured on bolt itself) - State after full drift excavation (a). State after stope under the drift has been excavated inducing high stresses on the back (b)

The results confirm the need for bolts with higher shearing capacity to support the on-ore drifts at the $440 \mathrm{~m}$ level, showing that an improved deformation compatibility and, hence, stable conditions in the evaluated scenario can be achieved by either a more compliant but lower yield strength design (D-bolts), or by a less compliant but higher yield strength design (\#7 rebars). 
A final design (Design 4) is evaluated for the case of a $200 \mathrm{~m}$ deep on-ore intersection that was also subject to mining-induced stresses. The goal of this exercise is to understand the falls of ground that occurred at Eleonore under these conditions as well as the role of secondary support. Figure 9 (top) shows the back condition of the intersection after it had been fully excavated (rebar installed $30 \mathrm{~cm}$ from the face), but before the stope below is mined.

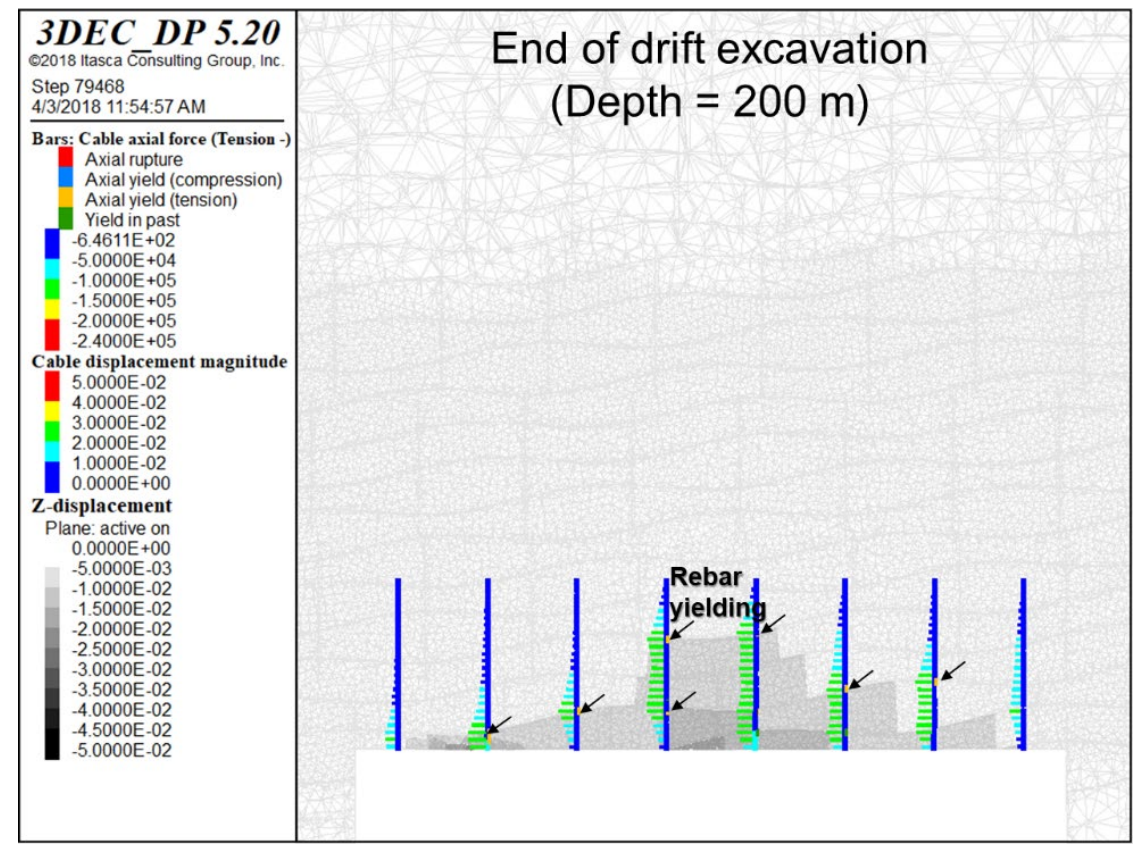

(a)

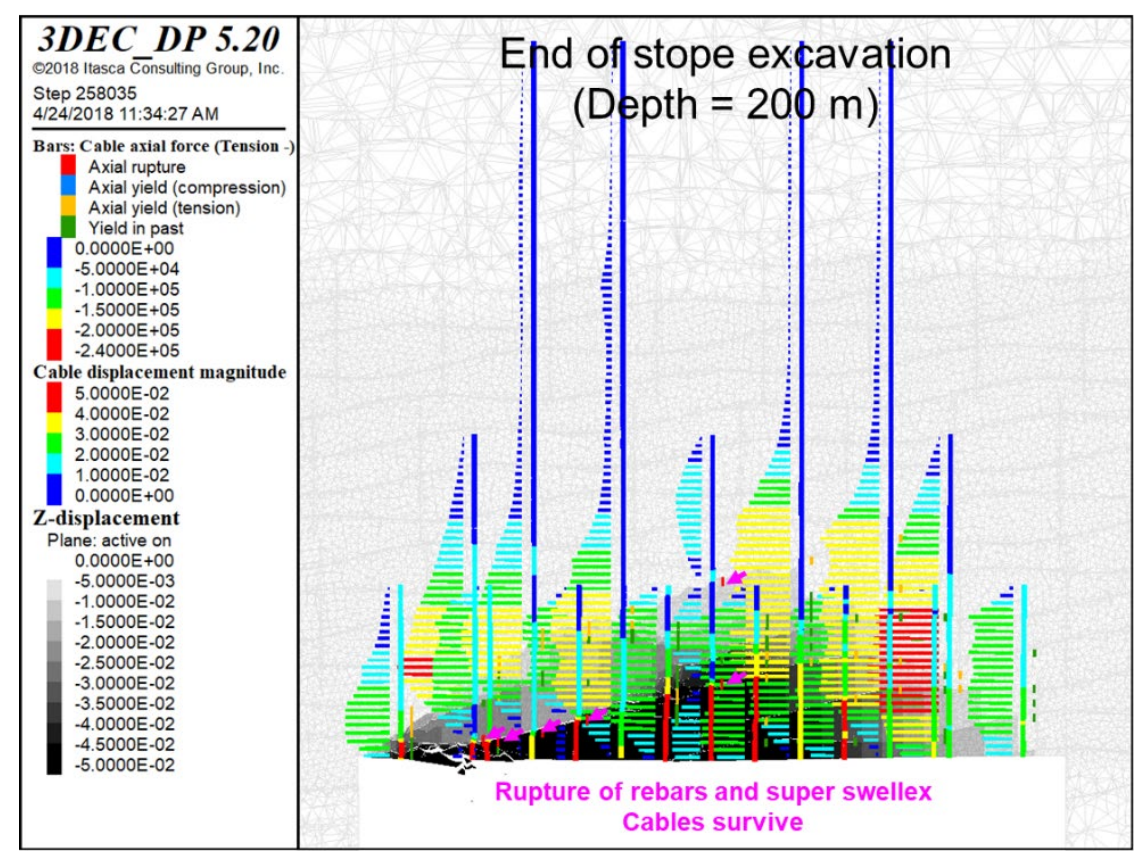

(b)

Figure 9 On-ore intersection at $200 \mathrm{~m}$ depth with Design 4. Rock vertical displacement (greyscale), bolt's axial force (bar graph on bolt's left side), and cable displacement (contoured on bolt itself) - State after full drift excavation (a). State after stope under the drift has been excavated inducing high stresses on the back (b) 
At this point, the rebars are being loaded (up to $\sim 150 \mathrm{kN}$ ) mostly in the central part of the back where most of the vertical displacement is taking place where they intersect the sub-horizontal joints. Yielding is observed in many of the rebars as their load capacity has already been reached and their stretching capacity is now being consumed. After equilibrium is achieved, the secondary support is installed ( $4.6 \mathrm{~m}$ super Swellex and $10 \mathrm{~m}$ cables), followed by excavation of the stope below. As higher stresses are induced in the back, the rebars get further loaded up to their maximum capacity. A wedge of ground is detaching from the back leading to the rupture of some rebars and super Swellex along its boundary due to intense local shearing and opening. While most of the cables survive and prevent part of the wedge from collapsing, both the primary and secondary support are compromised. Some rock fragments on the left side of the intersection are fully detached but would likely be bagged in the mesh. One of the most noteworthy results from the model is that only the lower half of the $10 \mathrm{~m}$ cables is actually exercised. This implies that shorter cables could provide the same level of support.

Overall, Design 4 is able to keep part of the back in place but with most of the ground support elements compromised and, hence, close to overall failure of the back. This indicates, as observed by the mine, that this support design was not adequate, especially for deeper levels.

The model illustrates how installation distance from the face dictates the amount of deformation the primary support will need to endure (as the support capacity is consumed), as support capacity can be saved for additional load/deformation episodes if the support is required to take less of the initial elastic relaxation (installed farther from the face).

\section{Conclusion}

A series of models were developed to back-analyse and understand past falls of ground at Eleonore Mine as well as to evaluate the adequacy of the current designs to handle future conditions as mining advances. The shallow dip and undulation of the sub-horizontal joints strongly impact the back behaviour in accesses, with joints susceptible to shearing and opening under high horizontal stresses. The results of the study elucidated that the falls of ground experienced at the mine (Design 1) are due to the bolts in the back (\#6 rebar) being heavily strained locally through sub-horizontal joint shearing as nearby stoping took place, causing them to rupture. The split-sets show much lower loads. This indicates, as observed by the mine, that the old support design was not adequate.

Higher deformation compatibility and shearing capacity were necessary to successfully support the drifts. D-bolts (Design 2) exhibit a more compliant response to shearing of sub-horizontal joints since they get exercised over longer sections, spreading out the strain localisation and allowing them to survive large deformations with high deformation capacity left.

Although stiffer, \#7 rebar (Design 3) offer a higher yield strength, allowing the excavation to remain stable even with higher demand by high mining induced stresses ( $90 \mathrm{MPa})$. With this design, both shorter and longer \#7 rebar provide significant contributions to the support system. Overall, this study elucidates that an improved deformation compatibility and, hence, stable conditions in the evaluated scenario can be achieved by either a more compliant but lower yield strength design (D-bolts), or by a less compliant but higher yield strength design (\#7 rebars).

The installation distance from the face dictates how much deformation the ground support must withstand during the excavation of the drift. Installing the primary support $0.3 \mathrm{~m}$ from the face subjects it to loads that yield the support prior to stoping and strain it significantly. If additional loads induced by stoping are expected in on-ore accesses, secondary support needs to be designed to sustain such additional demand with a clear understanding of how much support capacity is left in the primary support.

In the $200 \mathrm{~m}$ deep on-ore intersection studied, the upper half of $10 \mathrm{~m}$ cables is not being exercised, which is an indication that cables could be substituted with shorter cables and still provide similar support to the back of openings. 
Caution must be taken when modelling ground support in these types of conditions. As shown here, the ground support was locally exercised through sub-horizontal joint shearing as a result of mining-induced stresses; therefore, explicitly representing these joints as well as the ability of the rock between joints to fracture and bulk is required to more realistically resolve such strain localisation in the ground support. This case study illustrates how numerical models can be used to better understand the mechanisms and interactions between the rock and the ground aiding in the optimisation of support design under complex conditions.

\section{Acknowledgement}

The authors acknowledge the Eleonore ground control team for providing insights into the mine's ground behaviour in addition to qualitative input data, and the Eleonore management team for permission to publish this paper, with special thanks to Sophie Bergeron (Mine General Manager), Luc St-Arnaud and Adrienne Rispoli (Strategic Group). The authors also acknowledge the external review committee that helped guide this work and brought useful ideas and comments (Veronique Falmagne from Agnico Eagle, Brad Simser from Glencore and Patrick Andrieux from A2GC).

\section{Copyright notice}

Newmont Goldcorp - Proprietary

\section{References}

Bouzeran, L, Pierce, M, Jalbout, A \& Ruest, M 2019, 'Stoping sequence optimisation at Eleonore Mine based on stress analysis through horizon scale numerical modelling', in W Joughin (ed.), Proceedings of the Ninth International Conference on Deep and High Stress Mining, The Southern Africa Institute of Mining and Metallurgy, Johannesburg, pp. 253-266.

Bouzeran, L, Furtney, J, Hazzard, J, Lemos, JV \& Pierce, M 2016, 'Advanced 3DEC bolt model for simulation of ground support performance in highly fractured and bulked rock masses', in E Nordlund, TH Jones \& A Eitzenberger (eds), Proceedings of the Eighth International Symposium on Ground Support in Mining and Underground Construction, Luleå University of Technology, paper 210, pp. 268-278.

Damjanac, B, Board, M, Lin, M, Kicker, D \& Leem, J 2007, 'Mechanical degradation of emplacement drifts at Yucca Mountain - a modeling case study, part II: lithophysal rock,' International Journal of Rock Mechanics and Mining Sciences, vol. 44, pp. 368-399.

Garza-Cruz, TV \& Pierce, M 2014, 'A 3DEC model for heavily veined massive rock masses', Proceedings of the 48th US Rock Mechanics/Geomechanics Symposium, American Rock Mechanics Associated, Alexandria.

Garza-Cruz, TV, Pierce, M \& Kaiser, PK 2014, 'Use of 3DEC to study spalling and deformation associated with tunnelling at depth,' Proceedings of the Seventh International Conference on Deep and High Stress Mining (Deep Mining 2014), Australian Centre for Geomechanics, Perth, pp. 421-436.

Hoek, E \& Brown, ET 1980, Underground Excavations in Rock, The Institution of Mining and Metallurgy, London, pp. 93-101.

Itasca Consulting Group, Inc. 2014, PFC3D - Particle Flow Code in Three Dimensions, version 5, computer software, Itasca, Minneapolis.

Itasca Consulting Group, Inc. 2016a, 3DEC - Three-Dimensional Distinct Element Code, version 5.2, computer software, Itasca, Minneapolis.

Itasca Consulting Group, Inc. 2016b, Griddle ${ }^{T M}$, version 1.0, computer software, Itasca, Minneapolis.

Lan, H, Martin, D \& Hu, B 2010, 'Effect of heterogeneity of brittle rock on micromechanical extensile behavior during compression loading', Journal of Geophysical Research, vol. 115, doi:10.1029/2009JB006496.

Milne, DM, Pakalnis, RC \& Lunder, PJ 1996, 'Approach to the quantification of hangingwall behaviour', Transactions of the Institution of Mining and Metallurgy: Mining Technology, vol. 105, pp. A69-A74.

Oke, J \& Kalenchuk, K 2017, 'MDEng Factual Report \#1015-F1704-01: Geotechnical Mapping and Site Characterization', prepared for Goldcorp Inc., Eleonore Mine. 
